\title{
TEORES DE NUTRIENTES DO MAMOEIRO 'Improved Sunrise Solo 72/12' SOB DIFERENTES LÂMINAS DE IRRIGAÇÃO, NO NORTE FLUMINENSE ${ }^{1}$
}

\author{
FREDERICO TERRA DE ALMEIDA², SALASSIER BERNARDO ${ }^{3}$, CLÁUDIA SALES MARINHO $^{4}$, \\ SÉRGIO LÚCIO DAVID MARIN ${ }^{5}$, ELIAS FERNANDES DE SOUSA ${ }^{6}$
}

\begin{abstract}
RESUMO - Entre os fatores que limitam a produtividade do mamoeiro, destacam-se a disponibilidade de água e nutrientes minerais. Assim, o ajuste de uma lâmina de irrigação adequada para a cultura exige também o monitoramento do estado nutricional das plantas. O objetivo desse trabalho foi avaliar a resposta das diferentes lâminas de irrigação $(0 ; 40 ; 80 ; 120 ; 160 ; 200$ e 240\% da ETo) sobre os teores de nutrientes nas folhas do mamoeiro 'Improved Sunrise Solo 72/12'. As avaliações dos teores de nutrientes no mamoeiro foram realizadas em junho de 1999, retirando-se amostras de duas plantas de cada tratamento, das quais foram analisados, separadamente, o limbo e o pecíolo foliar. Os resultados indicam que os teores de N, P, K, Ca, Mg, B, Na, Fe e Cu, no limbo, e os teores de N, P, Ca, Mg, S, B, Na e Fe, no pecíolo, variaram significativamente com a lâmina de água aplicada. A concentração desses nutrientes em função das lâminas de irrigação foi explicada, na maioria dos casos, por regressões lineares, decrescentes para $\mathrm{N}, \mathrm{K}$ e Fe, e crescente para os demais nutrientes. A variação significativa dos teores de nutrientes, em função da irrigação, mostra a necessidade de estudos que permitam o ajuste da adubação à lâmina de irrigação empregada.
\end{abstract}

Termos para indexação: análise foliar, nutrientes, mamoeiro, irrigação.

\section{NUTRIENTS CONTENTS OF THE 'Improved Sunrise Solo 72/12' PAPAYA UNDER DIFFERENT IRRIGATION SHEETS IN THE NORTH REGION OF RIO DE JANEIRO STATE, BRAZIL}

\begin{abstract}
Among the factors that limit the productivity of the papaya tree, stand out the availability of water and mineral nutrients. Therefore, the adjustment of the appropriate irrigation depth for the culture also demands the accompaniment of the state nutritional of the plants. The objective of this work was to evaluate the response of the different irrigation depths $(0,40,80,120,160,200$ and $240 \%$ of ETo) on the amounts of nutrients in the leaves of the papaya tree "Improved Sunrise Soil 72/12". The evaluations of the amounts of nutrients in the papaya tree were accomplished in June of 1999, by removing samples of two plants of each treatment, from which were analyzed, separately, the leaf blade and the petiole leaf. The results showed that the amounts of N, P, K, Ca, Mg, B, Na, Fe and Cu in the leaf blade, and the amounts of $\mathrm{N}, \mathrm{P}, \mathrm{Ca}, \mathrm{Mg}, \mathrm{S}, \mathrm{B}, \mathrm{Na}$ and Fe in the petiole leaf, varied significantly with the depth of applied water. The concentration of those nutrients, as a function of irrigation depths, was explained, in most of the events, by linear regressions, decreasing for $\mathrm{N}, \mathrm{K}$ and $\mathrm{Fe}$, and increasing for the other nutrients. The significant variation of the amounts of nutrients, as a function of irrigation, shows the need of studies that allow the adjustment of the manuring to the employed irrigation depth.
\end{abstract}

Index terms: leaf analysis, nutrients, papaya tree and irrigation.

\section{INTRODUÇÃO}

A Região Norte Fluminense (NF) possui grande potencial de produção para frutíferas, incluindo o mamão. Além de apresentar situação logística apropriada, a região possui, também, condições edafoclimáticas semelhantes às das principais regiões produtoras de mamão do País (Marin et al., 1995). Todavia, a pouca tradição no cultivo do mamão e a ausência de informações sobre o seu comportamento na região dificultam investimentos mais expressivos na cultura.

Entre os fatores que limitam a produtividade do mamoeiro, destaca-se a disponibilidade de água e de nutrientes minerais, uma vez que o mamoeiro apresenta os processos de floração, crescimento e maturação dos frutos simultaneamente, exigindo um suprimento constante e adequado de água e nutrientes para atingir o potencial de produção (Cibes \& Gaztambide, 1978).

A importância da água relaciona-se tanto à sua falta quanto ao seu excesso. A restrição hídrica, além de reduzir o crescimento da planta, favorece a produção de flores masculinas e estéreis, reduzindo a produção de frutos. Por outro lado, o excesso de água no pé da planta diminui a aeração e afeta a absorção de nutrientes, o aparecimento de doenças, além de possibilitar a perda de nutrientes por lixiviação (Marin et al., 1995).

Há muita controvérsia na literatura sobre a parte da planta, limbo ou pecíolo foliar, que deve ser usada para avaliar o estado nutricional do mamoeiro. Alguns autores recomendam a

1 (Trabalho 160/2001). Recebido: 08/10/2001. Aceito para publicação: 04/06/2002. Trabalho financiado pela FENORTE.

2 D.S. Produção Vegetal, Professor Colaborador do Laboratório de Engenharia Civil (LECIV), UENF, Campos dos Goytacazes, RJ, CEP: 28015-620. (0XX24) 2722-4836. E-mail: fredterr@uenf.br

3 Ph.D. Irrigação e Drenagem, Prof. Titular do Laboratório de Engenharia Agrícola da UENF. (0XX24) 2726-3701. E-mail: salassie@uenf.br

4 D.S. Produção Vegetal, Profa. Associada do Laboratório de Fitotecnia da UENF. (0XX24) 2726-3742. E-mail: marinho@uenf.br

5 M.S. Fitotecnia, Técnico de Nível Superior do Laboratório de Fitotecnia da UENF. (OXX24) 2726-3742. E-mail: slmarin@uenf.br

6 D.S. Produção Vegetal, Prof. Associado do Laboratório de Engenharia Agrícola da UENF. (0XX24) 2726-3807. E-mail: efs@uenf.br 
análise do pecíolo para a avaliação do "status" de N (Awada, 1969), de P (Awada \& Long, 1969) e de K (Awada \& Long, 1971). Entretanto, Viégas (1997) verificou maior sensibilidade do limbo foliar para detectar a disponibilidade de $\mathrm{N}$ para as plantas. Pérez \& Childers (1982) observaram que o limbo foliar, também, foi mais sensível como indicador do nível de Mn no mamoeiro. Marinho (1999) verificou que a melhor parte da folha para indicar o estado nutricional do mamoeiro pode variar de acordo com o nutriente em questão. Para N, foi verificado que o pecíolo se mostrou mais efetivo em detectar oscilações na sua disponibilidade. Costa (1995) verificou que os teores médios de N na matéria seca do pecíolo variaram quando foram amostrados no período da seca e das chuvas, enquanto os teores no limbo se apresentaram mais estáveis.Os teores de $\mathrm{N}$ no pecíolo aumentaram bastante nas amostragens feitas na época das chuvas.

A má distribuição de chuvas no NF e a precipitação inferior à demanda hídrica do mamoeiro, próxima de $1500 \mathrm{~mm}$ anuais (Falaguasta, 1980), tornam a irrigação imprescindível ao cultivo do mamoeiro e, sendo assim, o conhecimento das interações entre irrigação e adubação é de extrema importância. Portanto, o objetivo desse trabalho foi avaliar o efeito das diferentes lâminas de irrigação sobre os teores de nutrientes nas folhas (limbo e pecíolo) do mamoeiro 'Improved Sunrise Solo 72/12', no município de Campos dos Goytacazes-RJ.

\section{MATERIAL E MÉTODOS}

O experimento foi desenvolvido no período de agosto de 1998 a dezembro de 1999, na Fazenda Experimental da Empresa de Pesquisa Agropecuária do Estado do Rio de Janeiro (PESAGRO-RJ), localizado na Região Norte do Estado do Rio de Janeiro, onde o solo em questão é classificado como Cambissolo de origem fluvial, pouco profundo, com drenagem moderada a imperfeita, e, ainda, segundo classificação de Köppen, possui clima do tipo Aw, com estações secas e chuvosas definidas.

A cultivar de mamoeiro utilizada foi a 'Improved Sunrise Solo 72/12', plantada em fileiras duplas, com espaçamento 3,6 x $2,0 \times 2,0 \mathrm{~m}$.

Foi adotado o delineamento experimental em blocos casualizados, com três repetições. A parcela experimental foi composta por cinco plantas úteis. Os tratamentos foram constituídos por sete lâminas de irrigação, ou seja, $0 ; 40 ; 80 ; 120 ; 160$; 200 e $240 \%$ da evapotranspiração de referência (estimada pelo tanque Classe A). As lâminas foram aplicadas por meio de um sistema de irrigação por microaspersão, com uma faixa molhada contínua.

Na época da implantação da cultura, a análise química do solo indicou a seguinte adubação de plantio, por cova: $350 \mathrm{~g}$ de superfosfato simples, $30 \mathrm{~g}$ de cloreto de potássio, $150 \mathrm{~g}$ de calcário e 5 L de esterco bovino curtido (Marin et al., 1995).

A adubação em cobertura foi baseada nas recomendações de Marin et al. (1995), sendo feitas alternadamente entre um mês e outro, uma adubação NK e outra NPK, ou seja, no $1^{\circ}, 3^{\circ}$, $5^{\circ}, 7^{\circ}, 9^{\circ}, 11^{\circ}, 13^{\circ}, 15^{\circ}$ mês fazia-se a mistura de $100 \mathrm{~kg}$ de sulfato de amônia, $50 \mathrm{~kg}$ de cloreto de potássio, aplicando $100 \mathrm{~g} \cdot \mathrm{pl}^{-1} \mathrm{da}$ mistura, e no $2^{\circ}, 4^{\circ}, 6^{\circ}, 8^{\circ}, 10^{\circ}, 12^{\circ}, 14^{\circ}, 16^{\circ}$ mês fazia-se a mistura de $100 \mathrm{~kg}$ de sulfato de amônio, $100 \mathrm{~kg}$ de superfosfato simples e $50 \mathrm{~kg}$ de cloreto de potássio, aplicando $100 \mathrm{~g} \cdot \mathrm{pl}^{-1}$ da mistura. Para controle de pragas, doenças e plantas daninhas, foram feitas constantes vistorias no pomar, sendo aplicados os defensivos necessários.

As avaliações dos teores de nutrientes no mamoeiro foram realizadas por meio da amostragem de folhas recém-maduras (com uma flor recém-aberta em sua axila) em junho de 1999. Foram retiradas amostras de duas plantas por parcela e analisados, separadamente, o limbo e o pecíolo foliar, sendo estes divididos logo após o corte da folha.

As duas partes das folhas foram, então, secas, em estufa de circulação forçada de ar, à temperatura de $70^{\circ} \mathrm{C}$, por 48 horas. Em seguida, o material foi triturado em moinho (tipo Wiley) com peneira de 20 mesh. A matéria seca, assim obtida, foi submetida às análises químicas. Os elementos analisados foram $\mathrm{N}, \mathrm{P}, \mathrm{K}, \mathrm{Ca}$, $\mathrm{Mg}, \mathrm{S}, \mathrm{B}, \mathrm{Cl}, \mathrm{Na}, \mathrm{Fe}, \mathrm{Cu}, \mathrm{Mn}$ e Zn. As análises foram realizadas de acordo com metodologias descritas por Malavolta et al. (1997) e Jones Jr. et al. (1991). O N foi determinado pelo método de Nessler (Jackson, 1965), após digestão da matéria seca com $\mathrm{H}_{2} \mathrm{SO}_{4} \mathrm{e} \mathrm{H}_{2} \mathrm{O}_{2}$. A produção de frutos foi avaliada por meio da pesagem individual dos frutos na colheita, durante o período de realização do experimento. Os dados foram submetidos a análises de variância. As regressões para as médias dos tratamentos foram testadas a $5 \%$ de significância.

\section{RESULTADOS E DISCUSSÃO}

Os teores de N, P, K, Ca, Mg, B, Na, Fe e Cu, no limbo, e os teores de $\mathrm{N}, \mathrm{P}, \mathrm{Ca}, \mathrm{Mg}, \mathrm{S}, \mathrm{B}, \mathrm{Na}$ e Fe, no pecíolo, variaram significativamente com a lâmina total aplicada (Tabela 1 e Figuras 1 e 2).

No presente trabalho, houve variação do $\mathrm{N}$ em relação às lâminas de irrigação, tanto no pecíolo (regressão quadrática) quanto no limbo (regressão linear). A significância da variação deste nutriente foi maior no pecíolo, corroborando as observações feitas por Costa (1995) e por Marinho (1999). Entretanto, ao contrário do observado por Costa (1995), os teores de N no pecíolo diminuíram com o aumento da lâmina de irrigação.

Para aqueles nutrientes cujos teores nas folhas variaram em resposta às diferentes lâminas de irrigação, as equações de regressão ajustadas foram em sua maioria lineares. Exceções foram verificadas para os teores de $\mathrm{N}$ e Fe no pecíolo e para os de $\mathrm{Ca}$ e $\mathrm{Cu}$ no limbo, que apresentaram equações de regressão quadráticas (Tabela 1 e Figuras 1 e 2).

Verificou-se, no limbo, um decréscimo no teor de $\mathrm{Ne} \mathrm{K}$, e um aumento nos teores dos demais nutrientes com o aumento da lâmina de irrigação. Todavia, no pecíolo, o teor de $\mathrm{N}$ apresentou decréscimo com o aumento das lâminas aplicadas, até 160\% da ETo, aumentando um pouco para as lâminas superiores. Comportamento semelhante foi observado para o Fe no pecíolo, enquanto, para os demais nutrientes, houve um aumento linear nos teores com o aumento da lâmina de irrigação.

A absorção de nutrientes pelas plantas está diretamente relacionada à disponibilidade destes e da água no solo. Dessa forma, um incremento na aplicação de água para uma mesma adubação pode levar a maior absorção de nutrientes pelas plantas, resultando em maiores teores de nutrientes nestas. Entretanto, o aumento na aplicação de água pode levar a menores teores de nutrientes na planta, em função de um maior cresci-

Rev. Bras. Frutic., Jaboticabal - SP, v. 24, n. 2, p. 547-551, agosto 2002 
mento e/ou produção, provocando um efeito de diluição dos nutrientes nos tecidos da planta e, ainda, devido a perdas de nutrientes por lixiviação.

Neste trabalho, os teores de $\mathrm{N}$ e $\mathrm{K}$ (no limbo) e $\mathrm{N}$ (no pecíolo) diminuíram com o aumento da lâmina de água. A variação dos teores de $\mathrm{N}$ no pecíolo foi inversa à variação da curva de produção, evidenciando que a exportação preferencial desse nutriente para os frutos pode ter contribuído para esse resultado. O Nitrogênio e o potássio são os nutrientes mais exportados para os frutos (Cunha \& Haag, 1980; Marinho, 1999).

Quanto aos outros nutrientes, que apresentaram crescimento significativo dos teores em função do aumento da lâmina de água, o aumento da disponibilidade de água no solo pode ter contribuído para otimizar sua absorção.

A obtenção de diferentes teores de nutrientes e também de produção em função de vários níveis de aplicação de água é fato verificado por vários autores, não só na cultura do mamão (Awada et al., 1979), como também na cultura do maracujazeiro (Carvalho, 1998), o que demonstra a existência de uma interação entre lâminas de irrigação e adubação como fatores de produ- ção.

Um outro fato a destacar é que, para a quase totalidade dos nutrientes, os teores encontrados para o tratamento de maior produção (T5) apresentaram valores inferiores aos de outros tratamentos, indicando uma necessidade de ajuste da adubação. Os teores de $\mathrm{N}$ e $\mathrm{K}$, abaixo dos citados como adequados na literatura, podem demonstrar uma possível deficiência nas adubações estabelecidas.

A produtividade encontrada para a lâmina de $160 \%$ ETo está dentro dos padrões de produtividade das principais regiões produtoras do País, embora os teores de $\mathrm{N}, \mathrm{K}, \mathrm{Ca}, \mathrm{Mg}, \mathrm{B}$ e $\mathrm{Cu}$ estivessem abaixo dos teores citados como adequados na literatura. Na avaliação do estado nutricional de várias cultivares de mamão para o Norte Fluminense, foram encontradas, também, boas produtividades, porém, com possível deficiência nutricional (Marinho, 1999), indicando que os níveis críticos ou as faixas de teores adequadas estabelecidos por Reuther \& Robinson (1986) e por Costa (1995), para o mamoeiro, podem não estar sendo representativos para essa região.

TABELA 1 - Teores médios dos nutrientes e a produtividade obtida (Prod.) para cada tratamento aplicado (Trat.), separadamente, para limbo e pecíolo - Campos - RJ, 1999

\begin{tabular}{|c|c|c|c|c|c|c|c|c|c|c|c|c|c|c|}
\hline \multicolumn{15}{|c|}{ LIMBO } \\
\hline \multicolumn{2}{|c|}{ Nutrientes } & $\mathrm{N}$ & $\mathrm{P}$ & $\mathrm{K}$ & $\mathrm{Ca}$ & $\mathrm{Mg}$ & $S$ & $\mathrm{Cl}$ & $\mathrm{Na}$ & B & $\mathrm{Fe}$ & $\mathrm{Cu}$ & $\mathrm{Mn}$ & $\mathrm{Zn}$ \\
\hline Trat. (\%ETo) & Prod. (t.ha $\left.{ }^{-1}\right)$ & - & -- & - - & $\left(\mathrm{g} \mathrm{kg}^{-}\right.$ & 1) - & -- & -- & - & - - & $--(\mathrm{n}$ & $\left.\mathrm{ng} \mathrm{kg}^{-1}\right)$ & - & - \\
\hline $\mathrm{T} 1(0)$ & 7,4 & 48,2 & 2,8 & 24,3 & 11,2 & 7,0 & 4,3 & 9,6 & 0,3 & 22,0 & 160,4 & 3,7 & 70,9 & 24,2 \\
\hline $\mathrm{T} 2(40)$ & 26,7 & 44,5 & 2,7 & 22,5 & 14,3 & 7,8 & 4,2 & 8,7 & 0,2 & 23,3 & 139,3 & 4,6 & 119,3 & 23,8 \\
\hline T3 (80) & 48,3 & 47,0 & 3,2 & 21,3 & 16,1 & 8,0 & 4,6 & 9,1 & 0,3 & 36,4 & 133,9 & 6,4 & 120,1 & 21,8 \\
\hline $\mathrm{T} 4(120)$ & 45,1 & 43,3 & 3,5 & 21,0 & 15,8 & 8,0 & 4,7 & 8,0 & 0,4 & 36,9 & 131,8 & 5,8 & 116,9 & 20,9 \\
\hline T5 (160) & 53,0 & 43,7 & 3,7 & 20,9 & 16,2 & 7,9 & 4,3 & 9,3 & 0,3 & 44,0 & 134,0 & 5,2 & 121,3 & 24,8 \\
\hline T6 (200) & 41,2 & 44,4 & 3,1 & 21,1 & 16,7 & 8,1 & 4,3 & 8,4 & 0,5 & 45,0 & 117,3 & 5,2 & 124,2 & 26,0 \\
\hline T7 (240) & 38,3 & 43,5 & 4,8 & 19,3 & 19,8 & 9,5 & 4,5 & 7,8 & 0,6 & 55,3 & 129,1 & 5,9 & 106,5 & 30,2 \\
\hline \multicolumn{2}{|c|}{ Valor de F } & 6,064 & 20,608 & 11,636 & 5,017 & 7,162 & 0,197 & 49,890 & 0,329 & 12,803 & 10,923 & 5,874 & 1,114 & 1,653 \\
\hline \multicolumn{2}{|c|}{$\mathrm{CV}(\%)$} & 5,3 & 15,2 & 8,1 & 12,4 & 12,2 & 8,7 & 18,6 & 35,9 & 29,6 & 10,1 & 15,6 & 32,8 & 31,0 \\
\hline \multicolumn{15}{|c|}{ PECÍOLO } \\
\hline T1 (0) & 7,4 & 10,5 & 2,4 & 27,7 & 10,9 & 3,4 & 2,1 & 12,3 & 0,2 & 12,1 & 32,8 & 1,6 & 29,6 & 12,1 \\
\hline $\mathrm{T} 2(40)$ & 26,7 & 9,3 & 2,3 & 25,3 & 11,4 & 3,8 & 2,6 & 15,6 & 0,3 & 13,4 & 24,8 & 2,0 & 42,0 & 11,9 \\
\hline T3 (80) & 48,3 & 8,7 & 2,8 & 27,6 & 13,3 & 4,5 & 3,8 & 16,4 & 1,0 & 14,0 & 22,9 & 2,6 & 45,5 & 9,5 \\
\hline $\mathrm{T} 4$ (120) & 45,1 & 8,2 & 2,9 & 26,2 & 12,5 & 5,2 & 4,0 & 18,3 & 1,3 & 14,4 & 25,6 & 1,9 & 45,2 & 7,6 \\
\hline T5 (160) & 53,0 & 7,0 & 3,5 & 25,2 & 13,4 & 4,6 & 3,8 & 16,0 & 1,0 & 14,6 & 22,8 & 1,7 & 47,3 & 12,2 \\
\hline T6 (200) & 41,2 & 7,5 & 3,3 & 24,9 & 14,3 & 5,4 & 3,6 & 18,1 & 1,3 & 15,2 & 25,1 & 2,3 & 39,1 & 25,1 \\
\hline T7 (240) & 38,3 & 7,4 & 4,7 & 24,5 & 15,6 & 5,2 & 4,3 & 14,3 & 1,4 & 16,2 & 17,6 & 1,6 & 36,7 & 9,3 \\
\hline \multicolumn{2}{|c|}{ Valor de F } & 4,937 & 11,262 & 0,646 & 10,655 & 20,158 & 17,198 & 20,722 & 0,710 & 31,305 & 7,635 & 0,025 & 0,147 & 0,466 \\
\hline \multicolumn{2}{|c|}{ CV (\%) } & 9,3 & 30,2 & 19,7 & 15,4 & 14,1 & 19,1 & 8,3 & 25,4 & 34,2 & 16,1 & 30,9 & 36,4 & 58,6 \\
\hline
\end{tabular}




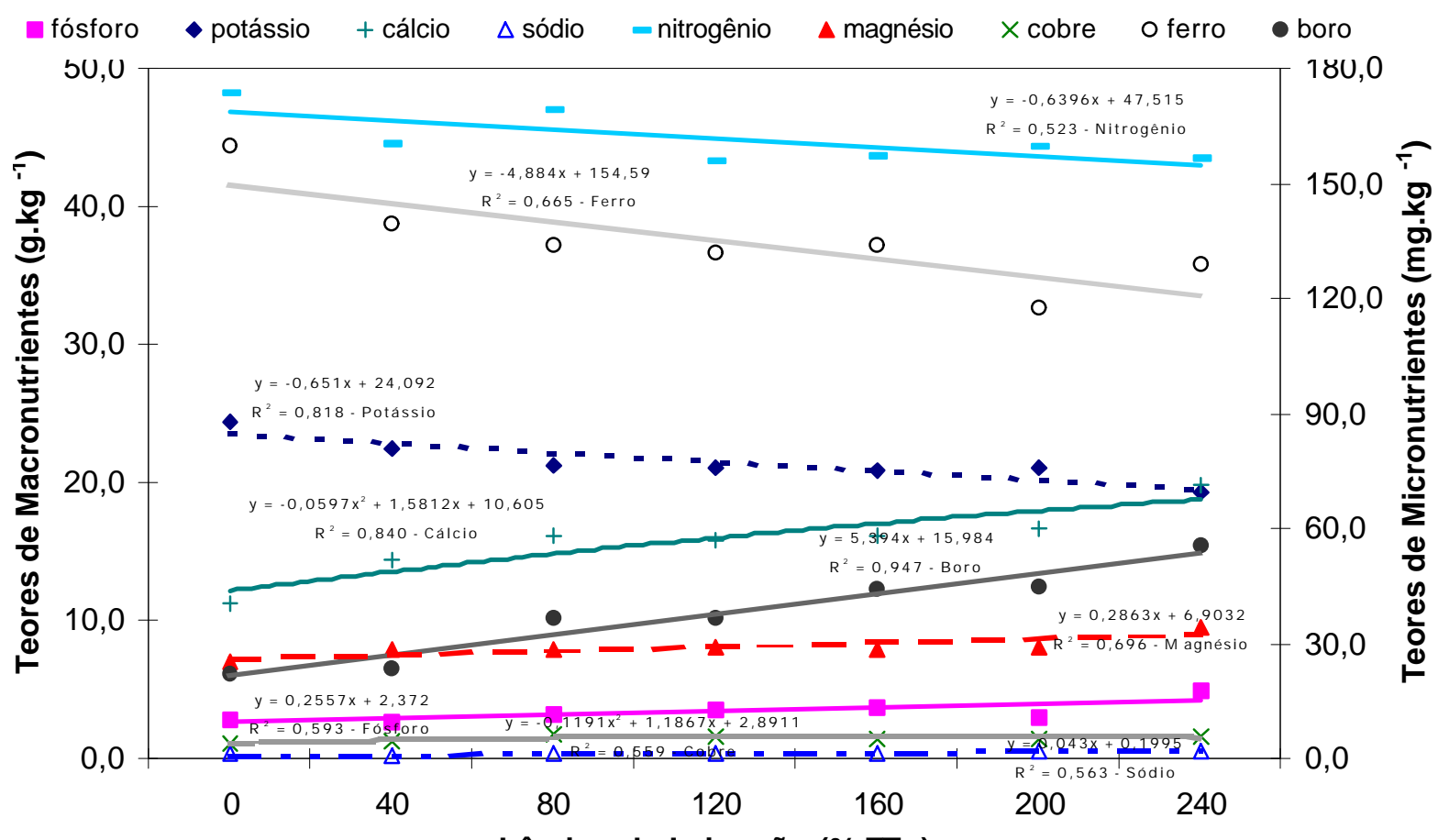

FIGURA 1 - Gráfico das equações de regressão dos teores de N, P, K, Ca, Mg, B, Na, Fe e Cu no limbo da folha, em função da lâmina de irrigação (\%ETo). Campos-RJ, 1999.

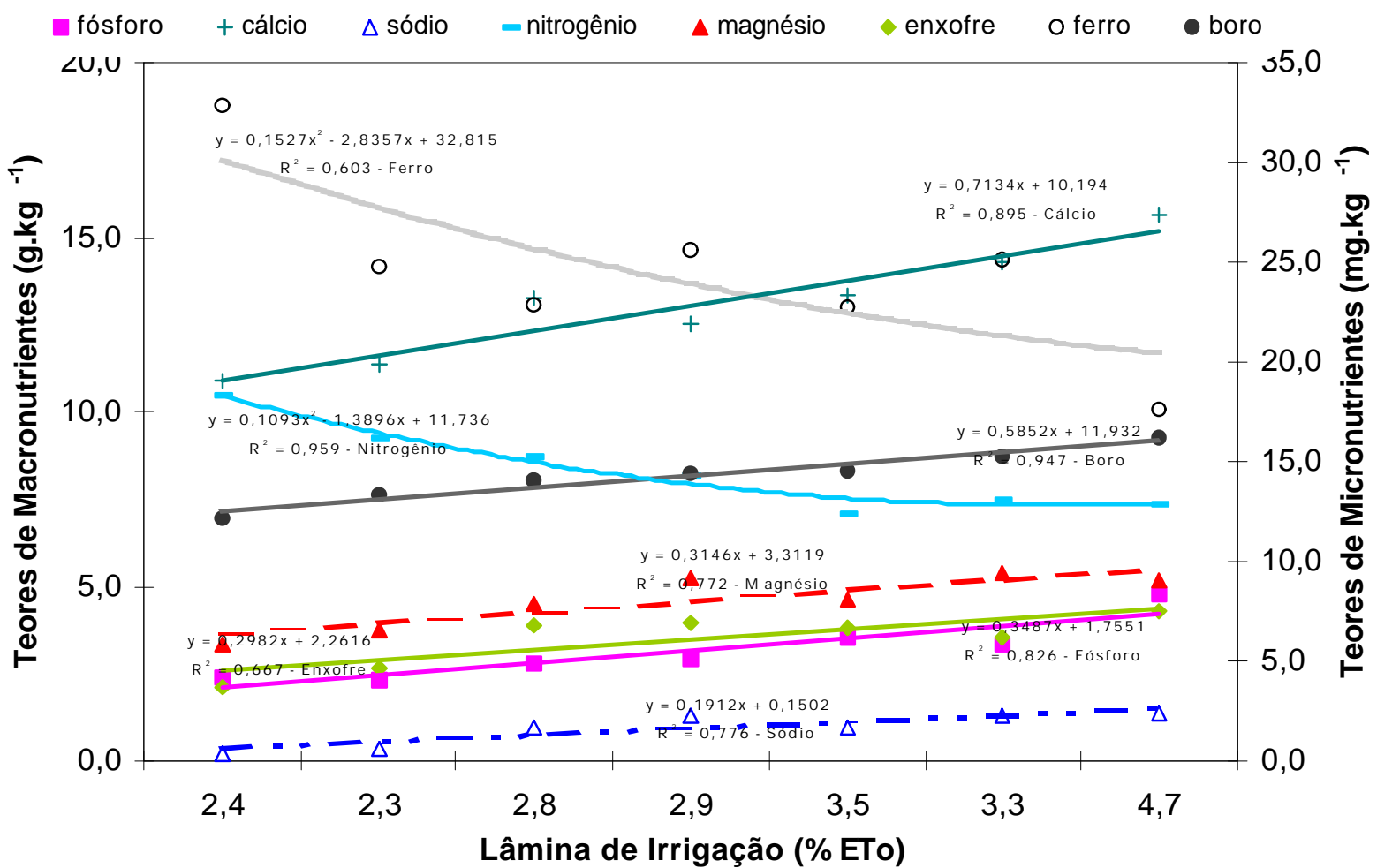

FIGURA 2 - Gráfico das equações de regressão dos teores de N, P, Ca, Mg, S, B, Na e Fe no pecíolo da folha, em função da lâmina de irrigação (\%ETo). Campos-RJ, 1999

\section{CONCLUSÕES}

1 - Os teores de N, P, K, Ca, Mg, B, Na, Fe e Cu, no limbo, e os teores de N, P, Ca, Mg, S, B, Na e Fe, no pecíolo, variaram significativamente com as lâminas aplicadas.

2 - As equações de regressão encontradas para a maioria dos nutrientes em função do aumento das lâminas de irrigação foram lineares, sendo decrescentes para $\mathrm{N}, \mathrm{K} \mathrm{e} \mathrm{Fe} \mathrm{e} \mathrm{crescentes} \mathrm{para} \mathrm{os}$ demais.

3 - A constatação da variação significativa da maioria dos teores de nutrientes com as diferentes lâminas aplicadas mostra a necessidade de ajuste das adubações em função das lâminas de 
água.

\section{REFERÊNCIAS BIBLIOGRÁFICAS}

AWADA, M. The selection of the nitrogen index in papaya tissue analysis. Journal of The American Society for Horticultural Science, Alexandria, v. 94, n. 4, p. 687-690, 1969.

AWADA, M., LONG, C. R. The selection of phosphorus index in papaya tissue analysis. Journal of The American Society for Horticultural Science, Alexandria, v. 94, n. 4, p. 501-504, 1969.

AWADA, M., LONG, C.R. The selection of the potassium index in papaya tissue analysis. Journal of The American Society for Horticultural Science, Alexandria, v. 96, n. 6, p. 74-77, 1971.

AWADA, M., WU, I. P., SUEHISA, R. H., PADGETT, M. M. Effects of drip irrigation and fertilization on vegetative growth, fruit yield, and mineral composition of the petioles and fruits of papaya. Honolulu: Hawaii Agricultural Experiment Station, University of Hawaii, 1979. 20 p. (Boletim Técnico, 103).

CARVALHO, A. J. C. DEComposição mineral e produtividade do maracujazeiro-amarelo em resposta a adubações nitrogenada $\mathrm{e}$ potássica sob lâminas de irrigação. 1998. 109 f. Tese (Doutorado em Produção Vegetal) - Centro de Ciências e Tecnologias Agropecuárias, Universidade Estadual do Norte Fluminense, Campos, 1998.

CIBES, H. R., GAZTAMBIDE, S. Mineral deficiency symptoms displayed of Puerto Rico papaya grow under controlled conditions. Journal Agriculture University, v. 62, n. 4, p. 413-423, 1978.

COSTA, A. N. Uso do sistema integrado de diagnose e recomendação (DRIS), na avaliação do estado nutricional do mamoeiro (Carica papaya L.) no Estado do Espírito Santo. 1995. 93 f. Tese (Doutorado em Fitotecnia) - Departamento de Fitotecnia, Universidade Federal de Viçosa, Viçosa, 1995.

CUNHA, R. J. P., HAAG, H. P Nutrição mineral do mamoeiro (Carica papaya L.) V. Marcha de absorção de nutrientes em condições de campo. Anais da ESALQ, Piracicaba, v. 37, p. 631-
$662,1980$.

FALAGUASTA, V. P. Exigências climáticas da cultura do mamão. In: ANAIS DO SIMPÓSIO BRASILEIRO SOBRE A CULTURA DO MAMOEIRO, 1., 1980, Jaboticabal, SP. Anais ... Jaboticabal: FCAV, 1980.p. 99-101.

JACKSON, M. L. Soil chemical analysis. New Jersey: Prentice Hall, 1965. 498p.

JONES JR, J. B.; WOLF, B.; MILLS, H. A.Plant Analysis Handbook: a practical sampling, preparation, analysis, and interpretation guide. Athens: Micro-Macro Publishing, 1991. 213p.

MALAVOLTA, E.; VITTI, G. C.; OLIVEIRA, S. A DE. Avaliação do estado nutricional das plantas: princípios e aplicações. 2.ed. Piracicaba: POTAFOS, 1997.319p.

MARIN, S. L. D.; GOMES, J. A.; SALGADO, J. S.; MARTINS, D. S.; FULLIN, E. A. Recomendações para a cultura do mamoeiro dos grupos Solo e Formosa no Estado do Espírito Santo. Vitória: EMCAPA, 1995. 57p. (Circular Técnica, 3).

MARINHO, C. S. Avaliação do estado nutricional e adubação do mamoeiro (Carica papaya L.) no Norte Fluminense. 1999. 80 f. Tese (Doutorado em Produção Vegetal) - Centro de Ciências e Tecnologias Agropecuárias, Universidade Estadual do Norte Fluminense, Campos, 1999.

PEREZ, A., CHILDERS, N. F. Growth, yield, nutrient content and fruit quality of Carica papaya L. under controlled conditions. Nitrogen effects. Journal of Agriculture of the University of Puerto Rico, Puerto Rico, v. 66, p. 71-79, 1982.

REUTHER, D. J., ROBINSON, J. B. Plant analysis: An Interpretation Manual. Melbourne: Inkatan Press, 1986. 218p.

VIÉGAS, P.R.A. Teores de nitrogênio em tecidos foliares, produção e qualidade de frutos de mamoeiro, em função da adubação nitrogenada. 1997. 62 f. Tese (Doutorado em Fitotecnia) Departamento de Fitotecnia, Universidade Federal de Viçosa, Viçosa, 1997. 